\title{
Variações sobre $O$ mercador de Veneza, de Ricardo Pais et al.
}

\author{
Paulo Eduardo Carvalho
}

\begin{abstract}
Titulo: $O$ mercador de Veneza (The Merchant of Venice, c. 1596). Autor: William Shakespeare. Tradução: Daniel Jonas. Versão livre: Ricardo Pais, Daniel Jonas. Encenação: Ricardo Pais. Cenografia: Pedro Tudela. Figurinos: Bernardo Monteiro. Música: Vitor Rua. Desenho de som: Francisco Leal. Desenho de luz: Nuno Meira. Assistência de encenação: Nuno M. Cardoso. Preparação vocal e elocução: João Henriques. Interpretação: Albano Jerónimo, António Durães, João Castro, Jorge Mota, José Eduardo Silva, Ligia Roque, Luis Araújo, Micaela Cardoso, Paulo Freixinho, Pedro Almendra, Pedro Frias, Pedro Jorge Ribeiro, Pedro Manana, Sara Carinhas. Produção: Teatro Nacional S. João. Local e data de estreia: Teatro Nacional S. João, 7 de Novembro de 2008.
\end{abstract}

Falar do encenador de um espectáculo como "autor" é como sabemos, tão só o modo provisório de assegurar um princípio de atribuição, a constituição operatória de um lugar ao qual seja possivel reconduzir a "leitura" desse mesmo espectáculo. Mas falar do Mercador de Veneza "de" Ricardo Pais não será tão só reconhecer o criador cénico como um princípio abstracto que nos permite a atribuição de um sentido ou até de uma intenção, porque é em si que efectivamente convergem as muitas contribuições, e "linguagens", de que ele não deixa de ser o principal "orquestrador". Também não se pretende, através deste recurso "autoral", sugerir que o encenador é uma espécie de simples tradutor dos sentidos da peça - "simples tradutor" é, aliás, uma expressão quase ignóbil que, por sua vez, rasura as profundas transformações introduzidas no texto durante a operação de reescrita, no caso deste Mercador de Veneza, tão mais intimamente realizadas em colaboração com as opções cénicas e dramatúrgicas do espectáculo quanto o próprio tradutor reconhece a contribuição decisiva do "discernimento insone" de Ricardo Pais e o modo como o texto final - e aquele publicado já não é exactamente o que se pode ouvir em cena... - é "em muito devedor de uma esgrima intelectual extenuante" (Jonas 2008: 166). Sem abandonar o texto - até porque ele é um dos mais poderosos e recorrentes materiais convocadas pela cena -, impõe-se reconhecer que os sentidos que se possam encontrar neste espectáculo resultam sobretudo da aplicação de práticas produtivas "sobre" o texto. Como recorda W. B. Worthen, "a representação faz mais do que simplesmente evocar, enunciar ou completar o texto; ela re-apresenta o texto numa variedade de incomensuráveis discursos visuais, fisicos ou corpóreos e cinéticos" (Worthen 1997: 63). Uma das coisas que melhor caracteriza as criações cénicas de Ricardo Pais é, justamente, o modo como ele habitualmente exponencia e articula de forma rigorosa e complexa essas múltiplas "práticas produtivas": a cenografia, os figurinos, a iluminação, a música, o fundo sonoro, a representação dos actores, etc.

No caso deste Mercador de Veneza, haverá, desde logo, que reconhecer que a particular conformação encontrada pela versão dramatúrgica se apresenta rica em consequências especificamente cénicas. A decisão de reordenar a sequência das cenas do texto de Shakespeare, de modo a criar dois blocos cuja autonomia é determinada pelo lugar da acção - Veneza e Belmonte -, promove toda uma outra dinâmica narrativa: ao mesmo tempo que intensifica a consequência de alguns núcleos temáticos, também investe os significantes visuais de uma responsabilidade acrescida no estabelecimento de ecos, paralelos e variações, confiando ao espectador um papel muito mais activo, atento e vigilante do que habitualmente acontece - o que não deixa de ter como consequência adicional a intensificação da já ostensiva teatralidade de toda a proposta resultante da dupla operação dramatúrgica e cénica.

No contexto da dinâmica muito particular com base na qual Ricardo Pais habitualmente desenvolve as suas colaborações artísticas, será justo reconhecer a responsabilidade do cenógrafo deste espectáculo, na definição de um lugar, um "habitáculo para pessoas e texto", mas não menos importante será também atentar no modo como o encenador acciona esse espaço, transformando-o efectivamente num "lugar contínuo de inesperadas reescritas" (as expressões são do próprio encenador, Pais 2006: 13). Aquilo que se poderá designar como a proposta cenográfica deste Mercador de Veneza assenta na articulação de três poderosos elementos, quase autónomos e solitariamente eloquentes, tanto na sua capacidade de metaforização como na sua virtualidade transformativa.

Um estrado colocado sobre o palco delimita o espaço dominante da representação, ao mesmo tempo que assinala e figura - na sua qualidade de "palco-dentro-do-palco" o modo como o espectáculo assenta em múltiplos e sucessivos desdobramentos teatrais que - fenómeno frequente em Shakespeare - permitem que o teatro pense o teatro ou, pelo menos, que o teatro se dê a ver - o que é também manifestação do entendimento barroco do mundo como um palco, que neste texto encontra formulação eloquente logo na primeira cena, na boca do mercador António: "0 mundo não passa de mundo, Graziano: / Um palco onde cada homem tem um papel, / 0 meu é triste" (Shakespeare: 2008: 15). A solução encontrada para o chão deste estrado - um jogo de desencontrados rectângulos pretos e brancos - funciona primeiro como obsessivo ponto de confluência óptica, para 


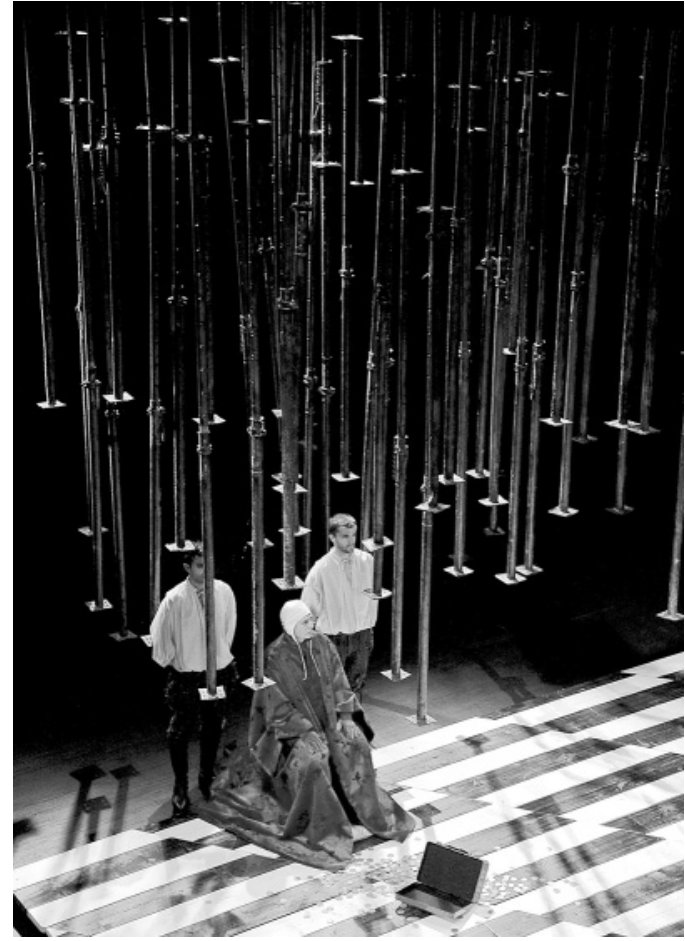

depois se abrir a infinitos desdobramentos de sentido: por um lado, o contraste acentuado entre o preto e o branco promove a sugestão dos violentos embates morais que a peça encena; por outro, a inevitável persistência do desalinhamento desses rectângulos pretos e brancos explicita a multiplicidade de ambivalências que o encenador leu no texto de Shakespeare, a ponto de afirmar, em momento de partilha com os actores, que o "grande tema do Mercador é a ambivalência - como é que se vive com ela, e a quantos níveis se vive com ela. Ambivalência de género, ambivalência sexual, ambivalência de desejo, ambivalência de missão, ambivalência de religião..." (Pais apud Sobrado 2008: 12). Por último - e tirando partido do esclarecimento prestado pelo próprio encenador quanto à génese da ideia (cf. Pais 2008: 6): a reprodução de um tecto florentino da época (encontrado, mais exactamente, no pormenor de um quadro de Andrea del Castagno, A Última Ceia, S. Apollonia, Florença, 1445-50) -, o chão deste tablado é assim espelho e reflexo de um tecto, o inverso do que deveria estar por cima, desse modo acompanhando tanto a sugestão enunciada pela parede espelhada ao fundo da cena como a da massa de ferrugentas escoras suspensas que ocupa, durante toda a primeira parte do espectáculo, o lado esquerdo da cena - e estes são os outros dois elementos dominantes.

A articulação entre aquela densa, labiríntica e também desencontrada cortina de escoras e o referido chão permite, ainda, figurar não só a indispensável alternância entre espaços exteriores e interiores, como também a sua poderosa contaminação. Ao suspender materiais que habitualmente servem para suster - cruciais na cidade flutuante por excelência que é Veneza - repete-se, de forma coerente, a lógica do inverso, ao mesmo tempo que, através da sua ostensiva condição enferrujada, se aponta, mais literalmente, para a presença próxima da água e, mais metaforicamente, para a corrosão de uma sociedade que só por oportunismo, e hipocrisia, se orgulha de albergar a diferença e a alteridade.

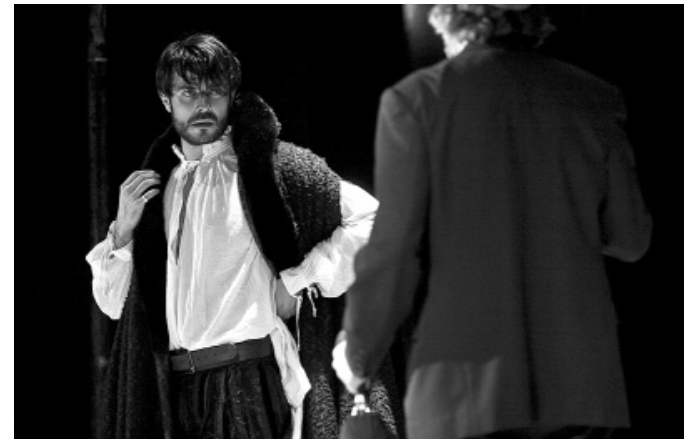

$<>$

$\checkmark$

O mercador de Veneza, de William Shakespeare, enc. Ricardo Pais, Teatro Nacional. S. João, 2008 < Pedro Jorge Ribeiro, Jorge Mota e Pedro Manana; > Albano Jerônimo e António Durães; $\checkmark$ Micaela Cardoso),

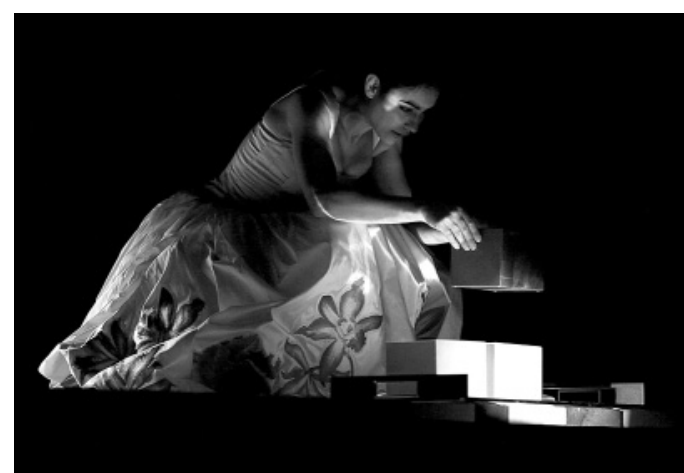
fot. João Tuna.
A já referida parede negra espelhada que ocupa grande parte do fundo da cena clarifica e sublinha a dinâmica autoreflexiva da ficção dramática. À imagem das transformações imprimidas ao chão do estrado - invadido não só pelos corpos e pelas roupagens dos actores, mas também, provisoriamente, por cadeiras e bancos - e à cortina de escoras - que, por vezes, servem de fonte sonora, quando tocadas, por exemplo, pelo guarda-chuva de Shylock, ou ganham movimento, quando accionadas por alguma das personagens, habitualmente num movimento de saida mais intempestiva -, também esta parede espelhada se revela dotada de um inesgotável dinamismo, através da abertura, num plano superior, de uma espécie de fenda, de altura muito variável. 0 recurso a este mecanismo permite ao encenador, simultaneamente, conquistar um outro espaço de representação - com a vantagem, difícil em teatro, de poder controlar o seu enquadramento - e de jogar num outro plano de representação, acrescentando o eixo vertical à horizontalidade dominante na experiência teatral. Até porque resulta de uma mais ostensiva intervenção do encenador, a utilização desta espécie de fissura horizontal permite ainda a introdução de outras variações: este é o espaço para figurar tanto a casa de Shylock, com Lancelote e Jessica, como a intervenção decisiva do Doutor Baltasar e do seu secretário, bem como, mais tarde, outras sequências situadas em Belmonte, com destaque para a escolha dos cofres e a magnífica cena ao luar de Jessica e Lorenzo, "Numa noite assim" - e ainda, num registo completamente distinto, a marcante rêverie de António, na segunda parte do espectáculo, invenção da dramaturgia que opera uma espécie de densa, mas poderosa, sintese narrativa e temática de quase toda a peça.

A eloquência simples mas majestosa do espaço de representação encontra um contraponto coerente, quase se diria amplificado, nos figurinos, que acompanham exemplarmente os gestos da encenação na criação de dinâmicas alternativas, sublinhando tanto a poderosa materialidade de Veneza (que encontra nas capas de brocado 

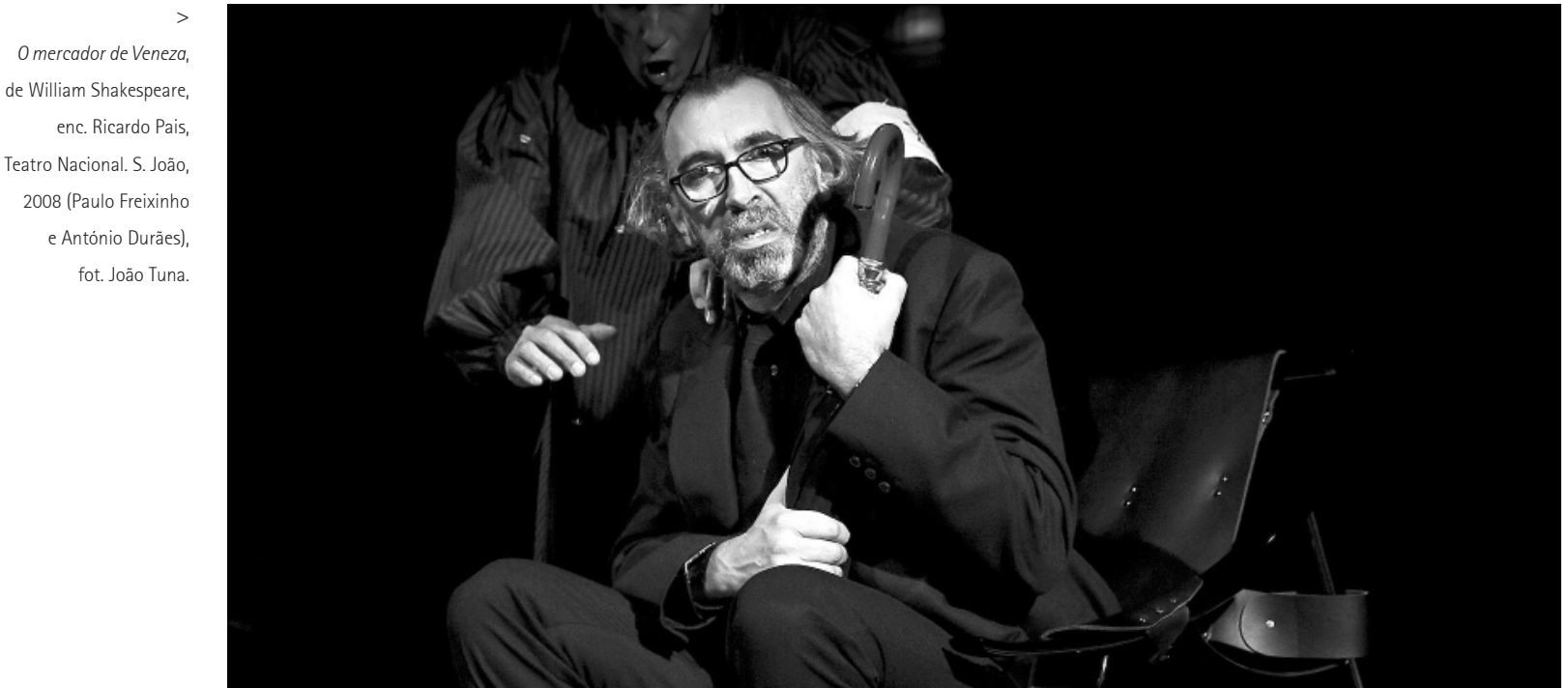

a sua mais fulgurante expressão), como a, só aparente, maior evanescência lírica de Belmonte. Intencional ou não, a beleza - haverá outra palavra? - dos vestidos com motivos florais de Pórcia e Nerrisa na segunda parte do espectáculo não é menos eloquente na demonstração da riqueza firmada - o encenador gosta de falar em "riqueza inerte" e "bens de raiz", por oposição aos "bens de mercância" - de Belmonte: com uma ironia que é quase irrisão, é como se as duas personagens - com destaque para Pórcia, com a sua entrega total ao disfarce - tivessem acabado de sair do atelier do Sr. Dior, no mesmo dia em que teriam ido às compras com outra princesa que também foi actriz, Grace de seu nome e pelo casamento de Mónaco, mas na sua anterior condição - enquanto Kelly imortalizada por desfilar vestidos que são outras tantas obras de arte nas comédias sombrias do mestre Hitchcock.

Para lá de muitos dos apontamentos mais individuais e pormenorizados, os figurinos funcionam como sinalização recorrente do modo como o desejo se manifesta nesta peça, em equação permanente entre o domínio do sentimento (e do erótico) e o domínio do financeiro (e do mercantil). Há também uma espécie de excesso, na riqueza das texturas e das silhuetas das roupagens dos venezianos e habitantes de Belmonte, que contrasta com a maior sobriedade, quando não ascetismo, do fato masculino e mais moderno de Shylock, numa figuração que introduz algum ecletismo, mas igualmente projecta a personagem para lá da sua condição ficcional, em direcção ao plano da história, em conformidade, aliás, com a ignominiosa estrela amarela cozida na lapela do seu casaco.

Curiosamente, o uso do fato masculino só volta a ser convocado para os opositores do "judeu" na cena do tribunal, Baltasar e o seu secretário, isto é, para os disfarces de Pórcia e Nerissa, como se mais do que a enunciação do preconceito e do estereótipo que atravessa toda a peça fosse a demagogia legalista que condena Shylock a atravessar os tempos e a percorrer a história, ainda tão perto de se poder dizer nossa contemporânea.

Naturalmente, toda esta matéria visual é animada por um conjunto de intérpretes notáveis de expressividade capazes de accionar a palavra com a mesma competência com que modulam dinâmicas relacionais, sugerem recortes psicológicos ou explicitam as forças morais em confronto - e por uma poderosa matéria sonora, tanto a nível da composição especificamente musical como da notação de ruídos vários, entre rangidos e o marulhar das águas. Resgatando António da condição secundária a que tradicionalmente é remetido - e apresentando-o como manifestação reprimida do desejo, tão mais chocante quanto se promove aqui a juventude viril da personagem -, a encenação multiplica possibilidades de confronto e de paralelismo, opondo o mercador a Shylock - retratado com uma dignidade que contorna tanto as tentações da comédia como os exageros do destino trágico - e a Pórcia - que no exercício do disfarce, na cena do tribunal, acompanha a já referida projecção de Shylock no curso da história, prefigurando a horrenda justificação para a solução do "extermínio". Toda a sequência do tribunal é, aliás, gerida de um modo que por completo esclarece como a derrota do "judeu" é também a sua vitória, pela denúncia que proporciona da cruel hipocrisia associada aos "cristãos".

0 que torna o espectáculo tão fulgurante e tão pertinente é justamente o modo como - à imagem da peça, atravessada por tensões e contradições, na sua produtiva multivocalidade - se apresenta como um objecto poderosamente teatral e, ao mesmo tempo, tenso e contraditório - o encenador talvez preferisse "ambivalente" -, habitado por uma grande diversidade de problemas associados aos valores morais, ao sexo, à religião e, só por preconceito, também à raça.

\section{Referências bibliográficas}

JONAS, Daniel (2008), "Nota à tradução", in William Shakespeare, O mercador de Veneza, Lisboa, Edições Cotovia, pp. 165-173.

PAIS, Ricardo (2006), "Todos os que escrevem", entrevistado por Pedro Sobrado, in Manual de leitura de Turismo infinito, Porto, TNSJ, pp. 9-11. - - (2008), "O mundo não passa de mundo", entrevistado por Paulo Eduardo Carvalho, in Manual de leitura de 0 mercador de Veneza, Porto, TNSJ, pp. 6-7.

SHAKESPEARE, William (2008), 0 mercador de Veneza, trad. Daniel Jonas, Lisboa, Edições Cotovia.

SOBRADO, Pedro (selecção e edição) (2008), "Quarenta e nove degraus", in Manual de leitura de 0 mercador de Veneza, Porto, TNSJ, pp. 10-13.

WORTHEN, W. B. (1997), Shakespeare and the Authority of Performance, Cambridge, C. U.P. 